\title{
Taponamiento cardíaco como complicación de derivación ventrículo atrial
}

\author{
Cardiac tamponade as a complication of ventriculo atrial shunt
}

\author{
Dr. Facundo Jorro Barón ${ }^{a}$, Dra. Alejandra Casanovas ${ }^{a}$, Dra. Elena Guaita ${ }^{a}$, Dra. Cecilia Bolasella, \\ Dra. Valeria Romboláa y Dr. Gustavo Debaisia
}

\section{RESUMEN}

El taponamiento cardíaco es una entidad poco frecuente en pediatría. Comunicamos un caso de taponamiento cardíaco por la acumulación de líquido cefalorraquídeo secundario a una válvula de derivación ventrículo-atrial (VDVA). Ingresó una niña de 11 meses de edad con dificultad respiratoria de $12 \mathrm{~h}$ de evolución, afebril, taquicárdica, portadora de una válvula de derivación ventrículo atrial por hidrocefalia desde hacía dos meses. En el ecocardiograma se observó derrame pericárdico y la punta de la VDVA en la cavidad pericárdica. Se realizó la extracción de la VDVA y su recolocación en la desembocadura de la vena cava superior en la aurícula derecha. La paciente presentó buena evolución con un ecocardiograma posterior sin evidencia de derrame. Ante un paciente con VDVA que se presente con clínica de descompensación de algún tipo, se debería descartar en primer lugar que la causa no sea secundaria a la VDVA.

Palabras clave: derivación ventrículo-atrial, taponamiento cardíaco, derrame pericárdico.

\section{SUMMARY}

Cardiac tamponade is an uncommon disorder in pediatric patients. We report a case of cardiac tamponade secondary to accumulation of cerebrospinal fluid due to ventriculo-atrial derivation (VAD) disfunction. An 11-month-old girl was assisted because of respiratory distress and tachycardia, without fever. She had a ventriculoatrial derivation, because of hydrocephalus since two month earlier. The echocardiogram showed a pericardial effusion and the distal VAD located inside the right cardiac ventricle. The distal VAD was retired and replaced between superior cava vein and right atrium. The patient recovered ad integrum without pericardial effusion. In cases of patients with VAD presenting a clinical disorder, it should be ruled out VAD dysfunction or inappropriate placement. Key words: cardiac tamponade, ventriculoatrial shunt, pericardial effusion.

doi:10.5546/aap.2011.e1

a. Hospital General de Niños Pedro de Elizalde.

Correspondencia:

Dr. Facundo Jorro Barón:

jorrobox@yahoo.com.ar

Conflicto de intereses: Ninguno que declarar.

Recibido: 10-6-2011

Aceptado: 23-9-2011

\section{INTRODUCCIÓN}

El taponamiento cardíaco es una entidad poco frecuente en pediatría, que ocasiona el compromiso de la función diastólica y puede progresar al shock obstructivo o al paro cardíaco, si no se diagnostica y trata oportunamente. ${ }^{1,2}$ Se debe a la acumulación de líquido pericárdico por diversas etiologías, entre las cuales cabe mencionar a los tumores malignos, las infecciones bacterianas o virales, la tuberculosis, los traumatismos o bien ser idiopático. Se han comunicado casos con derrame pericárdico poscolocación de accesos venosos por perforación del ventrículo o de la aurícula derecha por la punta del catéter de la VDVA.,4

Presentamos el informe de un caso de taponamiento cardíaco por la acumulación de líquido cefalorraquídeo secundario a la perforación del ventrículo derecho por la punta de un catéter de la VDVA.

\section{CASO CLÍNICO}

Se presentó a la consulta, en el Servicio de Emergencia (SE) del Hospital General Pedro de Elizalde, una niña de 11 meses de edad con dificultad respiratoria de 12 h de evolución, sin fiebre. Entre sus antecedentes personales se destacaban: prematurez (32 semanas de edad gestacional al nacimiento), con peso adecuado según la edad gestacional; estuvo internada en el Servicio de Neonatología durante dos meses, donde se le realizó una colostomía por haber presentado una malformación anorrectal (ano imperforado). A los tres meses de vida presentó meningitis por Klebsiella pneumoniae, con hidrocefalia secuelar, por lo que a los nueve meses es intervenida quirúrgicamente para la colocación de una VDVA.

$\mathrm{Al}$ ingreso al SE se registró taquicardia (frecuencia cardíaca [FC] de 200/min) y taquipnea (frecuencia respiratoria [FR] de 120/min), sin rales, con murmullo vesicular conservado en ambos campos pulmonares. Entre los exámenes complementarios, la radiografía de tórax mostraba cardiomegalia sin infiltrados pulmonares y ECG con ritmo sinusal. Una expansión con solución fisiológica a $20 \mathrm{ml} / \mathrm{kg}$ produjo leve disminución de 
la FC. Ingresó a la Unidad de Terapia Intensiva, donde se le realizó un ecocardiograma que mostró abundante líquido en la cavidad pericárdica. Realizada la pericardiocentesis se obtuvieron 15 $\mathrm{ml}$ de un líquido claro (citoquímico con $\mathrm{pH} 7,8$; proteínas+++, 32 elementos). Luego del procedimiento, la FC descendió a 120/min y la FR a 40/ min. Se tomaron tres hemocultivos y un cultivo de líquido pericárdico, se medicó con ceftriaxona a $80 \mathrm{mg} / \mathrm{kg} /$ día, vancomicina a $40 \mathrm{mg} / \mathrm{kg} /$ día y $\mathrm{AAS}$ a $40 \mathrm{mg} / \mathrm{kg} /$ día. Al día siguiente se realizó una radiografía de tórax y un nuevo ecocardiograma, donde se observó persistencia del derrame pericárdico y punta del catéter de la VDVA en la cavidad pericárdica (Figuras 1 y 2). Con el diagnóstico de derrame pericárdico, secundario a la perforación miocárdica por la punta del catéter, se ingresó a la paciente al quirófano de cirugía cardiovascular. Se realizó la extracción del catéter de derivación ventriculoatrial y su recolocación; la punta de catéter quedó ubicada en la unión entre la vena cava superior y la aurícula. Los cultivos fueron negativos y se suspendió la terapia con antibióticos.

FIGURA 1. Radiografía de tórax en donde se observa catéter de derivación ventrículo-atrial (flecha).

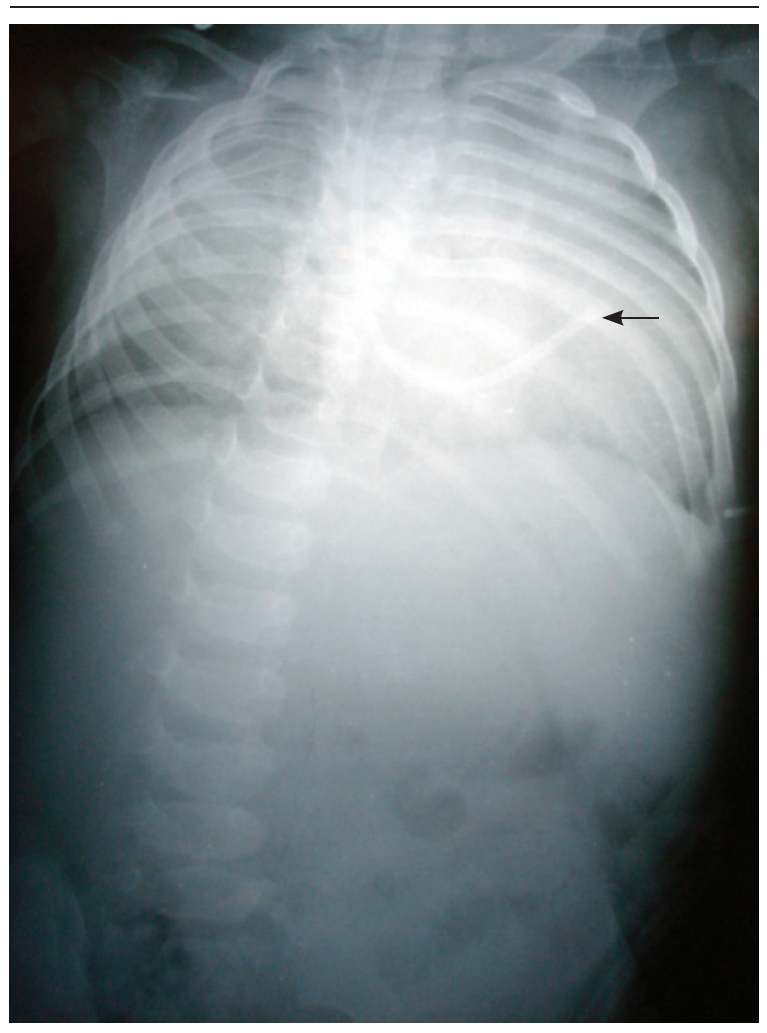

La paciente presentó buena evolución, con un ecocardiograma posterior sin evidencia de derrame pericárdico.

\section{COMENTARIOS}

Ante la presencia de un paciente con signos de taponamiento cardíaco se deben considerar distintos diagnósticos diferenciales, los cuales varían según la cronología de presentación de la sintomatología. La paciente presentada tuvo un inicio agudo, por lo que se descartó la pericarditis aguda, ya que el líquido extraído fue estéril y con baja celularidad; igualmente se realizó cobertura con antibióticos que fueron suspendidos con los resultados de los cultivos de líquido pericárdico y de sangre. Dentro de las restantes causas a descartar en pacientes con taponamiento cardíaco, se encuentran las enfermedades del tejido conectivo, como la artritis reumatoide juvenil, que en raras ocasiones se presenta de esta forma, y es de difícil diferenciación con la pericarditis producida por el lupus eritematoso. También se debería descartar la fiebre reumática aguda, la pericarditis urémica en los pacientes con insuficiencia renal y la producida por las enfermedades neoplásicas. En la cirugía, del corazón con pericardiotomía puede observarse un derrame pericárdico, que puede progresar al taponamiento en las semanas posteriores al procedimiento. Es recomendable recabar información de eventuales traumatismos debido a la posibilidad de contusiones pericárdicas. ${ }^{1,2}$

La colocación de válvulas de derivación ventricular es una práctica frecuente en pediatría. A

FIGURA 2. Ecocardiograma que muestra sombra acústica en cavidad pericárdica que corresponde a punta de catéter distal enclavada en ventrículo derecho (flecha).

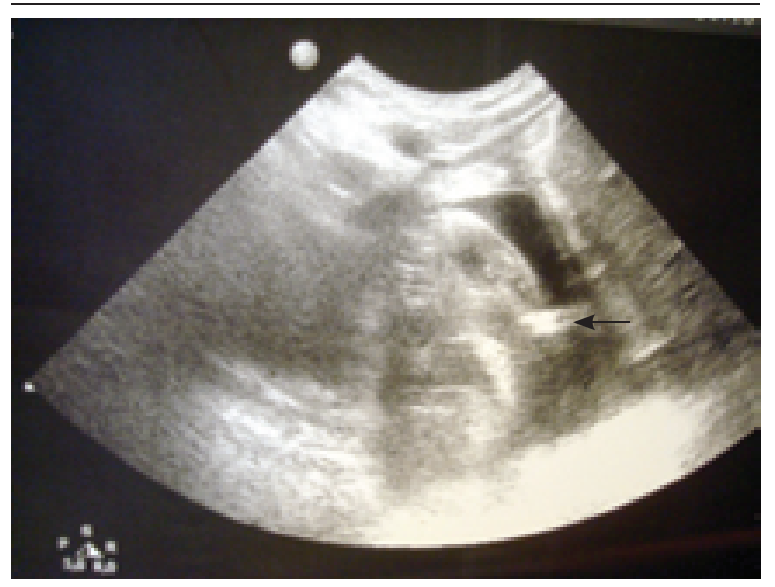


lo largo de los años, la técnica y las opciones de colocación del catéter distal han variado y la derivación ventrículo-peritoneal ha pasado a ser la opción más utilizada por su menor tasa de complicaciones en comparación con el resto. Existen contraindicaciones para derivar el líquido cefalorraquídeo (LCR) al peritoneo; la existencia de una colostomía se halla dentro de las contraindicaciones relativas, al igual que el antecedente de una cirugía abdominal previa. El fallo de una derivación ventrículo-peritoneal por múltiples infecciones o complicaciones mecánicas abdominales es indicación de derivar la salida de líquido cefalorraquídeo hacia la aurícula derecha. Las complicaciones que siguen a la colocación de estos dispositivos, ya sea a corto o a largo plazo, se deben a infecciones o a falla mecánica. La infección del shunt ocurre en un 5-10\% de los procedimientos y es mayor en neonatos. Habitualmente, la infección se presenta en los primeros seis meses de la colocación del dispositivo, y debe ser considerada ante un paciente con fiebre persistente. En la mayoría de los casos requiere la extracción del dispositivo y drenaje ventricular externo. ${ }^{4}$

La complicación mecánica es un problema importante, especialmente en el primer año de colocación del dispositivo. La tasa de fallo, incluyendo infección, es de aproximadamente $40 \%$ en el primer año, con un 5\% en los años subsiguientes. ${ }^{5,6}$ La principal falla mecánica se produce por obstrucción del catéter en su porción ventricular, en segundo lugar se ubica la ruptura del dispositivo en un $15 \%$ de los casos, también se comunican migraciones de parte o de todo el dispositivo $(7,5 \%)$ y sobredrenaje $(7,5 \%) .^{7}$

En el caso particular de las derivaciones ventrículo-atriales encontramos, además de las complicaciones descriptas, las producidas por su localización intracardíaca. Dentro de este grupo se han comunicado casos de migración hacia la arteria pulmonar con hipertensión pulmonar y cor pulmonale, ${ }^{8}$ ruptura intracardíaca con manifestaciones de trombosis o sin ellas, ${ }^{9}$ perforación miocárdica y posterior tamponamiento cardíaco. ${ }^{3}$

Por lo tanto, ante un paciente con derivación ventricular que se presente con clínica de descompensación cardíaca de algún tipo, se debe descartar, en primer lugar, que su causa no sea secundaria a la derivación.

\section{Agradecimientos}

A la Dra. Silvia Santos por la revisión del manuscrito.

\section{BIBLIOGRAFÍA}

1. Bernstein D. Enfermedades del pericardio. En:Kliegman RM, Behrman RE, Jenson HB, Stanton BF, eds. Nelson Tratado de Pediatría 18a ed. Barcelona: Elsevier. 2009; Págs.1972-75.

2. Wessel DL, Fraisse A. Postoperative care of the pediatric cardiac surgical patient: general considerations. En: Nichols D. Roger's Textbook of Pediatric Intensive Care, $4^{\mathrm{a}} \mathrm{ed}$. Filadelfia: Lippincott Williams \& Wilkins. 2008; Pág.1168.

3. El-Eshmawi A, Onakpoya U, Khadragui I. Cardiac tamponade as a sequela to ventriculoatrial shunting for congenital hydrocephalus. Tex Heart Inst J 2009;36(1):58-60.

4. Veetai L. Methods and complications in surgical cerebrospinal fluid shunting. Neurosurg Clin N Am 2001;(36):685-93.

5. Apsner R, Winkler S, Schneeweiß B, Hörl WH. The shampoo clue: two cases of infection of a ventriculoatrial shunt. Clin Infect Dis 2000;31(6):1518-19.

6. Drake JM, Kestle JR, Milner R, Cinalli G, et al. Randomized trial of cerebrospinal fluid shunt valve design in pediatric hydrocephalus. Neurosurgery 1998;43(2):294-303.

7. Chumas P, Tyagi A, Livingston J. Hydrocephalus - what's new? Arch Dis Child Fetal Neonatal Ed 2001;85(3):F149-54.

8. Berhouma M, Vallée B. Pulmonary hypertension and migrated ventriculoatrial shunt. Rev Prat 2011;61(5): 602.

9. Mori T, Arisawa M, Fukuoka M, Tamura K, et al. Management of a broken atrial catheter migrated into the heart: a rare complication of ventriculoatrial shunt - case report. Neurol Med Chir (Tokyo) 1993;33(10):713-5. 